\title{
Rare complication of a percutaneous long line
}

\author{
Shiva Shankar, ${ }^{1}$ Sagarika Ray, ${ }^{2}$ Manish Gupta ${ }^{3}$
}

'Department of Neonatal Medicine, The Shrewsbury and Telford Hospital NHS Trust, Telford, UK

${ }^{2}$ Department of Neonatal Medicine, The Shrewsbury and Telford Hospital NHS Trust, Telford, UK

${ }^{3}$ Department of Paediatrics, The Shrewsbury and Telford Hospital NHS Trust, Telford, UK

Correspondence to

Dr Shiva Shankar,

sshankar@nhs.net

Accepted 15 May 2018

\section{DESCRIPTION}

An infant of a diabetic mother required 20\% glucose infusion for hypoglycaemia. This was initially administered via an umbilical venous catheter, which was subsequently dislodged. As the infant was over 24 hours old at the time, attempts at reinsertion of an umbilical venous catheter were not considered due the risk of infection. Consequently, the glucose infusion was administered through a percutaneous long line inserted in the left ankle. An abdominal radiograph revealed the tip to be at the level of L5 (figure 1). Eight hours following the start of the infusion, the left leg was noted to be pale, cool to touch and poorly perfused. The femoral pulse was weaker on that side with absence of the popliteal, posterior tibial and dorsalis pedis artery pulses. The long line was removed. The site of insertion of the long line was reinspected and noted to be posteroinferior to the medial malleolus.

The vascular surgeons at a tertiary centre advised starting an intravenous heparin infusion prior to transfer. Following transfer to the tertiary centre, Doppler sonography showed a dampened waveform in the left superficial femoral artery and absence of any arterial thrombus. Perfusion returned to the left leg within a week despite continuing to have a weak femoral pulse and absent distal arterial pulses in that limb.

Percutaneous long lines inserted in the lower limbs should aim to have the tip ideally in the inferior vena cava. Long lines inserted in the left lower limb have

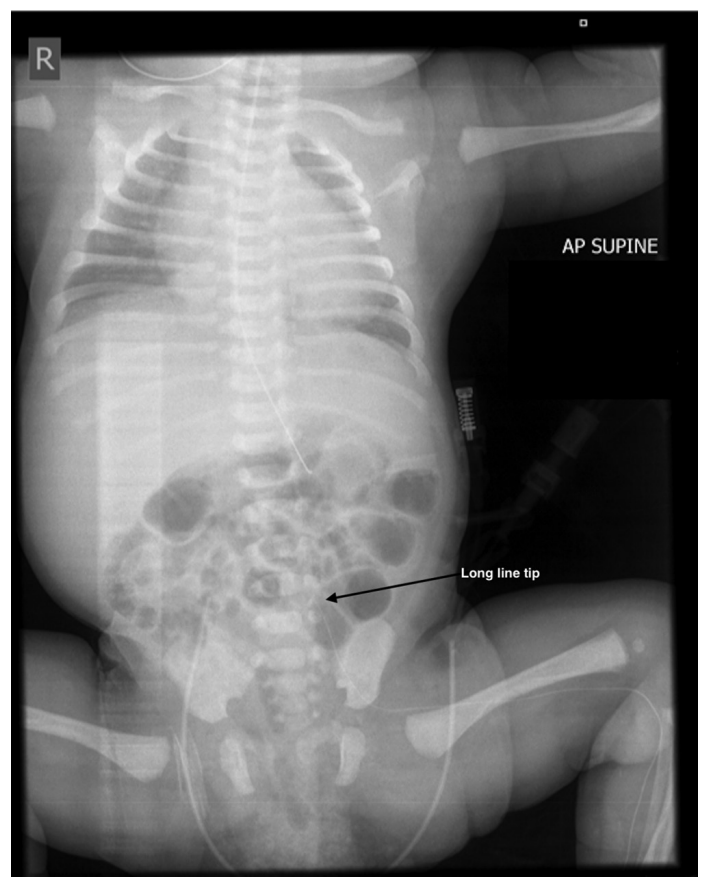

Figure 1 Radiograph showing tip of the long line.

\section{Learning points}

- In the case of a percutaneous long line being inserted in the left lower limb, the tip at the level of $L 5$ and to the left of the spine on a radiograph may not necessarily indicate its placement in a vein. In such cases, consider possible arterial cannulation and check for perfusion and pulses in that limb while considering removal of the line. Obtaining a blood gas from the line to check if it is arterial or evaluating with vascular ultrasound may be useful.

- If there are signs of arterial compromise to the lower limb following insertion of a percutaneous long line, it is important to remove the line immediately, regardless of location.

the additional requirement to cross the midline at the level of L5 to ensure that the tip has traversed the left common iliac vein and not travelled up the left ascending lumbar vein. Malposition in the ascending lumbar vein is a recognised complication of long lines being inserted in the left lower limb. This should be suspected through typical radiographic signs such as any loop or bend in the course of the line which may occur due to the local anatomy in the left ileofemoral vein $^{1}$ or tracking of radio-opaque dye alongside the left side of the spine in the anatomical position of the left ascending lumbar vein. ${ }^{2}$

The line tip in this infant may have been suspected to be in the ascending lumbar vein although it did not show all the typical radiographic signs. Moreover, arterial compromise of the left lower limb and the tip having not crossed the midline suggest that the tip of the long line may have been situated in the common iliac artery. This case illustrates the importance of having a strong suspicion of accidental insertion of a percutaneous long line into an artery if the tip does not cross the midline at the level of L5 and does not have any loop or bend or tracking of radio-opaque dye alongside the spine to indicate its malposition within the ascending lumbar vein. ${ }^{12}$ In such cases, it may be helpful to obtain a blood gas from the line to ascertain whether arterial or venous or evaluate with vascular ultrasound, if available.

Contributors SS identified the case and drafted the initia manuscript. SS and SR reviewed the manuscript. SS, SR and MG approved the final manuscript.

Funding The authors have not declared a specific grant for this research from any funding agency in the public, commercial or not-for-profit sectors.

Competing interests None declared.

Patient consent Parental/guardian consent obtained. 


\section{Images in...}

Provenance and peer review Not commissioned; externally peer reviewed.

(c) BMJ Publishing Group Ltd (unless otherwise stated in the text of the article) 2018. All rights reserved. No commercial use is permitted unless otherwise expressly granted.

\section{REFERENCES}

1 Schoonakker BC, Harding D. Radiological sign of a long line in the ascending lumbar vein. Arch Dis Child 2005;90:982.

2 De A, Imam A. Long line complication: accidental cannulation of ascending lumbar vein. Arch Dis Child Fetal Neonatal Ed 2005;90:F48.

Copyright 2018 BMJ Publishing Group. All rights reserved. For permission to reuse any of this content visit

http://group.bmj.com/group/rights-licensing/permissions.

BMJ Case Report Fellows may re-use this article for personal use and teaching without any further permission.

Become a Fellow of BMJ Case Reports today and you can:

- Submit as many cases as you like

- Enjoy fast sympathetic peer review and rapid publication of accepted articles

- Access all the published articles

- Re-use any of the published material for personal use and teaching without further permission

For information on Institutional Fellowships contact consortiasales@bmjgroup.com

Visit casereports.bmj.com for more articles like this and to become a Fellow 